\title{
Does cervical favourability and mode of delivery affect the maternal and perinatal outcome in eclampsia?: a cohort study
}

\author{
Momina Zulfeen ${ }^{1 *}$, Radha Tatapudi ${ }^{2}$, Ravella Sowjanya ${ }^{3}$
}

\begin{abstract}
${ }^{1}$ Department of Obstetrics and Gynecology, Kasturba Medical College, Manipal, Karnataka, India ${ }^{2}$ Department of Obstetrics and Gynecology, GITAM University, Vizag, Vishakapatnam, India ${ }^{3}$ Department of Obstetrics and Gynecology, Siddhartha Medical College, Vijayawada, Andhra Pradesh, India
\end{abstract}

Received: 23 May 2019

Accepted: 02 July 2019

*Correspondence:

Dr. Momina Zulfeen,

E-mail: mominazulfeen@gmail.com

Copyright: () the author(s), publisher and licensee Medip Academy. This is an open-access article distributed under the terms of the Creative Commons Attribution Non-Commercial License, which permits unrestricted non-commercial use, distribution, and reproduction in any medium, provided the original work is properly cited.

\begin{abstract}
Background: To study the association between cervical favorability at admission and maternal, perinatal outcome. To study the association between mode of delivery and maternal, perinatal outcome in eclampsia.

Methods: This was a retrospective cohort study carried out in a tertiary hospital. All women (92) admitted with antepartum eclampsia from April 2015 to April 2016, with >32 weeks gestation, reassuring foetal heart and no other complications were included in the study. They were divided into two cohorts delivery, maternal and perinatal outcomes were compared between the two groups.

Results: Group with favourable cervix achieved higher vaginal deliveries. Perinatal mortality and morbidity were significantly higher in patients with unfavourable cervix (mortality 39.6\% and 20.5\% respectively, p: 0.046: morbidity $25.6 \%$ and $7.8 \%$ respectively, p: 0.033 ), more so in vaginal delivery (RR 2.355). However there was no significant difference in maternal morbidity. Higher induction-to-delivery interval was the major contributory factor. Conclusions: Perinatal outcome was worse in patients with unfavourable cervix at induction. This can be attributed to increased induction to delivery time and vaginal route of delivery. Prolonged induction should be avoided in eclampsia.
\end{abstract}

Keywords: Eclampsia, Pre-eclampsia, Perinatal outcome, Hypertension, Mode of delivery

\section{INTRODUCTION}

Eclampsia (Greek word for lightening) is defined as the presence of new-onset grand mal seizures in a woman with preeclampsia. Eclampsia is an obstetric emergency accounting for $12 \%$ of maternal deaths and $16-31 \%$ of perinatal deaths. ${ }^{1}$

The incidence of eclampsia in India varies from $0.5 \%$ to $1.8 \% .^{2}$ In India maternal mortality ranges from $8-14 \%$ and perinatal mortality varies from $24-34 \%$. The first step in management of eclampsia is supportive care to prevent maternal injury. Next step is to prevent recurrent convulsions (universally accepted drug of choice being $\mathrm{MgSO} 4$ ), following which due attention must be given to control high blood pressure. ${ }^{3}$ Eclampsia causes severe maternal and perinatal complications. The definitive treatment for eclampsia is understood to be termination of pregnancy.

Even though a certain percentage of these women do come with spontaneous labour, majority require some form of labour induction. Labour must be induced once the patient is initiated on $\mathrm{MgSO} 4$ therapy. In the absence 
of any obstetric contraindication induction of labour should be done. ${ }^{4}$ But caesarean delivery is essential if the patient develops status eclampticus or blood pressure remains uncontrolled.

Most women with hypertension develop eclampsia before term. These women therefore are usually not in labour and require induction. Eclampsia by itself is not an indication for caesarean. Caesarean becomes essential during the course of labour for maternal and foetal causes like foetal distress, abruption, failed induction, uncontrolled seizures etc.

Sibai BM considers it best to perform caesarean routinely for women with less than 30 weeks of gestation and bishops score less than $5 .^{5}$ It is ideal to cut short the second stage during vaginal birth and also incidence of foetal distress being higher, operative vaginal delivery is more frequent. Some contend that in eclampsia, delivery should occur within 12 hours of the onset of convulsions. ${ }^{6}$ Pritchard et al, has advocated delivery of the patient as soon as convulsions are controlled and the patient is conscious, and certainly within 48 hours of the initial convulsion. ${ }^{4}$ Incidence of caesarean deliveries in eclampsia varies from $26.7-71 \% .{ }^{7,8}$ Immediate cure does not promptly follow delivery by any route in eclamptic women. ${ }^{9}$ In non eclamptic women, serious morbidity is less common when delivery is vaginal. Although there are no large randomized controlled trials conducted to evaluate the optimum method of delivery in eclampsia, mode of delivery is an obvious contributing factor in the outcome of eclampsia. A recent randomized controlled pilot study by Seal SL et al, concluded that early caesarean is not associated with better outcomes, although neonatal outcomes showed a trend toward improvement with early caesarean delivery. ${ }^{10}$

Cervical favourability at admission is a major determinant of success of vaginal delivery and outcome. Thus we have conducted a cohort study to see the association between cervical favourability at admission, mode of delivery and maternal, foetal outcome in eclampsia.

The objective of this study was to study the association between cervical favourability at admission and maternal, foetal outcome in eclampsia. And to study the association between mode of delivery and maternal, foetal outcome in eclampsia.

\section{METHODS}

This was a retrospective cohort study conducted in tertiary public hospital, South India, from April 2016 to April 2017. A total 112 cases of eclampsia were identified.

\section{Inclusion criteria}

- Gestation age $>32$ weeks
- $\quad$ Singleton pregnancy

- Reassuring foetal heart rate on cardiotocograph

- Cephalic presentation

- No other obstetric complications.

\section{Exclusion criteria}

- Presence contraindications to vaginal delivery (e.g. Contracted pelvis, malpresentations, placenta praevia)

- Contraindication to induction, anomalous fetuses

- IUGR with abnormal Doppler

- Comorbid medical conditions such as heart disease, diabetes mellitus or chronic renal disease and complications of eclampsia at presentation (e.g. HELLP syndrome, renal failure etc.).

We included a total of 92 cases in the study, which were divided into two cohorts based on Bishop's score (BS) of $<6$ (Group I) and $\geq 6$ (Group II).

Cohorts were comparable for baseline characteristicsage, parity, booked or un-booked, convulsion to admission interval, no. of convulsions, BP at admission, consciousness level at admission, mean gestation age and birth weight. All women received magnesium sulphate as anticonvulsant as per the institutional protocol: Pritchard regimen. If there was recurrence of convulsions, another $2 \mathrm{~g}$ IV 20\% MgSO4 is given IV. MgSO4 continued for 24 hours postpartum, with clinical monitoring and periodic assessment of knee jerk, respiratory rate and urine output. Serum magnesium levels not monitored. Antihypertensive was given if systolic blood pressure $\geq 160$ or diastolic blood pressure $\geq 110 \mathrm{mmHg}$, targeting BP between 140-160 $\mathrm{mmHg}$ and diastolic blood pressure between 90-110 $\mathrm{mmHg}$.

IV labetalol was the drug of choice in severe hypertension and was given in the doses of $20-80 \mathrm{mg}$ in increments, up to a maximum dose of $300 \mathrm{mg} / \mathrm{day}$. Oral nifedipine or labetalol was used to maintain the target blood pressure. IV fluids were restricted to $85 \mathrm{~mL} /$ hour.

Induction was based on cervical favourability with prostaglandins or oxytocin. Labour accelerated with oxytocin in active phase of labour. Foetal monitoring was done in active phase of labour by intermittent auscultation. Epidural analgesia was not used in labour.

\section{Outcomes measures}

Primary outcome measures included mode of delivery, maternal mortality, maternal morbidity rate, perinatal mortality and perinatal morbidity.

Secondary outcome measures included success of induction, induction to delivery interval and total $\mathrm{MgSO} 4$ dose given. 
Maternal morbidity or maternal events documented were respiratory depression (Respiratory rate $>12, \mathrm{O}_{2}$ saturation $<92 \%$ ), pulmonary oedema (diagnosed by clinical findings, chest $\mathrm{X}$ ray, renal failure (diagnosed by oliguria/anuria with rising serum creatinine), hepatic failure (diagnosed by clinical findings, serum bilirubin and liver enzyme values), coagulopathy (diagnosed by bleeding manifestations and coagulation profile), puerperal febrile morbidity ( temperature of $>101 \mathrm{~F}$ on 2 separate occasions), HELLP syndrome, Abruptio placentae, Cerebrovascular accident and PPH. Neonatal Morbidity was marked by Apgar score $<7$ at 5 minutes, delivery room intubation, NICU admission for $>7$ days.

\section{Statistical analysis}

SPSS 20 was used to compare the outcomes between the groups. Numerical variables were compared between groups by Student unpaired t-test and categorical variables by Fisher exact test or Chi square test as appropriate. A 2 sided pvalue of $<0.05$ was considered statistically significant with $95 \%$ confidence interval.

\section{RESULTS}

The incidence of eclampsia in our institute was $1.8 \%$.

Table 1: Comparison of baseline maternal and neonatal characteristics. Both groups were comparable for baseline characteristics.

\begin{tabular}{|c|c|c|c|}
\hline Variable & Group I $n=48$ & Group II n=44 & $p$ value \\
\hline Age in years & & & 1.117 \\
\hline$<20$ & 8 & 11 & \\
\hline $20-25$ & 34 & 29 & \\
\hline $26-30$ & 6 & 4 & \\
\hline$>30$ & 0 & 0 & \\
\hline Mean GEST age in weeks & 34.94 & 35.34 & 1.117 \\
\hline Antenatal care & & & 0.123 \\
\hline Booked & 6 & 11 & \\
\hline Unbooked & 42 & 33 & \\
\hline Parity & & & 1.00 \\
\hline Primi & 42 & 40 & \\
\hline Multi & 5 & 4 & \\
\hline Convulsion admission time & & & 0.374 \\
\hline$\leq 1 \mathrm{H}$ & 1 & 3 & \\
\hline $1-5 \mathrm{H}$ & 39 & 31 & \\
\hline$>5 \mathrm{H}$ & 8 & 10 & \\
\hline \multicolumn{4}{|l|}{$\mathrm{BP}$ in $\mathrm{mmHg}$} \\
\hline $\mathrm{SBP} \geq 160$ & 12 & 10 & 0.765 ( 2 sided $)$ \\
\hline $150-160$ & 21 & 24 & \\
\hline$\leq 150,>90$ & 14 & 9 & \\
\hline$\leq 90$ & 1 & 1 & \\
\hline DBP & & & 0.508 \\
\hline$\geq 110$ & 13 & 9 & \\
\hline $100-110$ & 21 & 26 & \\
\hline$\leq 100,>60$ & 13 & 8 & \\
\hline$<60$ & 1 & 1 & \\
\hline No. of convulsions before admission & 2.40 & 2.64 & 0.158 (equality of means) \\
\hline Consciousness level at admission & & & 0.521 \\
\hline Alert & 33 & 29 & \\
\hline Irritable & 7 & 10 & \\
\hline Obtunded comatose & 8 & 5 & \\
\hline Birthweight in $\mathrm{kg}$ & & & 0.091 \\
\hline$<1.5$ & 15 & 22 & \\
\hline $1.5-2.5$ & 15 & 22 & \\
\hline$>2.5$ & 10 & 15 & \\
\hline
\end{tabular}




\section{Maternal and perinatal outcome}

The groups were comparable with respect to baseline characteristics. Table 1 shows the comparison of baseline maternal and neonatal characteristics. We had 48 patients belonging to $\mathrm{BS}<6$ and 44 patients belonging to $\mathrm{BS}>6$. Both groups were comparable.

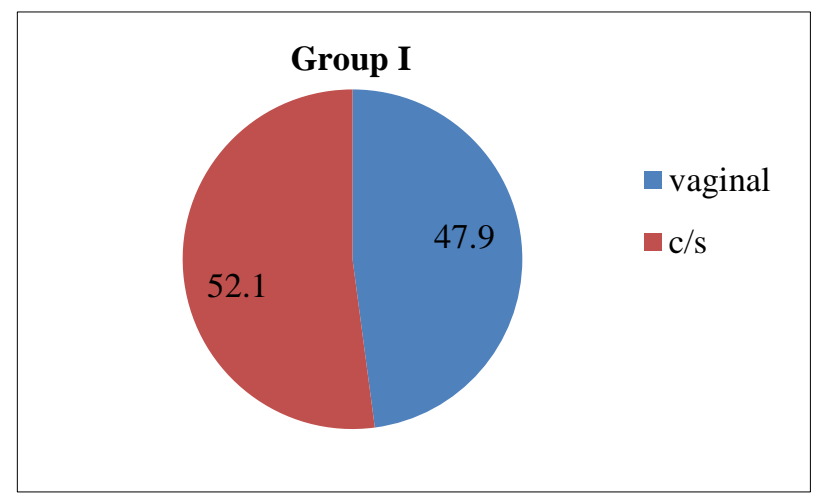

Figure 1: Bishop's score versus mode of delivery. Group 2 with favourable cervix had achieved higher vaginal deliveries.

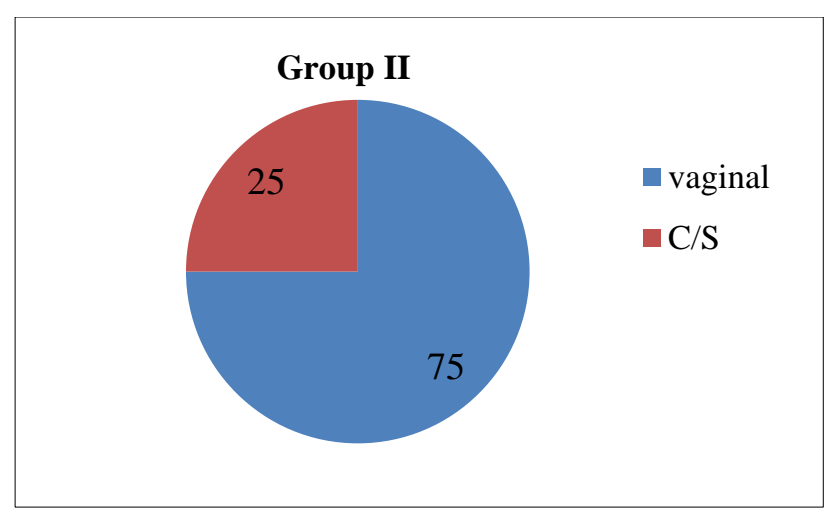

Figure 2: Bishop's score versus mode of delivery. Group 2 with favourable cervix had achieved higher vaginal deliveries.

Figure 1 shows a pictorial representation of the success of induction in both groups. Group II with favourable cervix had more vaginal deliveries indicating greater success of induction with favourable cervix $(47.9 \%$ in BS $>6$ - Figure 1 and $75 \%$ in $\mathrm{BS}<6$ Figure 2).

Table 2: Outcome versus bishops score (in percentages). Group with favourable Bishop score had better perinatal outcome.

\begin{tabular}{|lllll|}
\hline Outcome in percentage & Group 1 BS $<6$ & Group 2 BS $>6$ & P value & Significance \\
\hline Maternal morbidity & 37.5 & 25 & 0.260 & Insignificant \\
\hline Perinatal mortality & 39.6 & 20.5 & 0.046 & Significant \\
\hline Perinatal morbidity & 34.4 & 8.3 & 0.033 (fisher exact) & Significant \\
\hline
\end{tabular}

Table 3: Comparison of maternal outcome measures between groups, no significant difference found.

\begin{tabular}{|llll|}
\hline Complication & Group I $n=18$ & Group II $n=10$ & P value \\
\hline Ventilator support & $2(11.1 \%)$ & $3(30 \%)$ & 0.663 \\
\hline Pulmonary oedema & $0(0 \%)$ & $1(10 \%)$ & 0.478 \\
\hline Renal failure & $1(5.6 \%)$ & $1(10 \%)$ & 1.00 \\
\hline Coagulation failure & $2(11.1 \%)$ & $1(10 \%)$ & 1.00 \\
\hline Cerebrovascular accident & $2(11.1 \%)$ & $2(20 \%)$ & 1.00 \\
\hline PPH & $3(16.7 \%)$ & $0(0 \%)$ & 0.24 \\
\hline HELLP & $6(33.3 \%)$ & $1(10 \%)$ & 0.11 \\
\hline Abruptio placentae & $2(11.1 \%)$ & $1(10 \%)$ & 1.00 \\
\hline
\end{tabular}

Table 4: Outcome versus mode of delivery in group 1.

\begin{tabular}{|lllll|}
\hline Outcome Group I $(\mathbf{b s}<6)$ & Vaginal $(\%)$ & C/s $(\%)$ & P value & Significance \\
\hline Maternal morbidity & 26 & 48 & 0.117 & Insignificant \\
\hline Perinatal mortality & 56.5 & 24 & 0.021 LR - 5.397 & Significant \\
\hline Perinatal morbidity & 26.66 & 25 & 1.00 & Insignificant \\
\hline
\end{tabular}

Table 2 describes the outcomes in each group. Maternalmorbidity was $38.3 \%$ and $25.60 \%$ in group 1 and group 2 respectively (p- 0.260). Although maternal morbidity was higher in $\mathrm{BS}<6$, this difference was not statistically significant (Table 2). 
Individual outcome measures are depicted in Table 3. Maternal events included respiratory depression requiring ventilator support, pulmonary oedema, renal, coagulopathy, HELLP syndrome, Abruptio placentae, Cerebrovascular accident and $\mathrm{PPH}$.

Tables 4, 5 show maternal and perinatal outcomes in groups 1 and 2 respectively. Perinatal mortality and morbidity were significantly higher in group-I (mortality $39.6 \%$ and $20.5 \%$ respectively, p: 0.046 : morbidity $25.6 \%$ and $7.8 \%$ respectively, p: 0.033 ), more so in vaginal delivery (p 0.021, RR 2.355, LR 5.397) as shown in Table 4 and 5.

\section{Secondary analysis}

Two contributing factors of importance, induction to delivery interval and total $\mathrm{MgSo} 4$ dose, were compared between the groups to establish their importance in the outcome (Table 6).

Induction-to-delivery interval was significantly higher in the group with unfavourable cervix and was associated with higher perinatal mortality (p: 0.021). Table 7 shows the mean induction to delivery interval with respect to perinatal mortality.

Table 5: Outcome versus mode of delivery in group 2.

\begin{tabular}{|lllll|}
\hline Outcome Group II (bs>6) & Vaginal $(\%)$ & C/S (\%) & p value & Significance \\
\hline Maternal morbidity & 25 & 27.27 & 1.00 & Insignificant \\
\hline Perinatal mortality & 24.24 & 9.09 & 0.411 & Insignificant \\
\hline Perinatal morbidity & 6.8 & 10 & 1.00 & Insignificant \\
\hline
\end{tabular}

Table 6: Significantly higher induction to delivery interval and mean MGSO4 dose in group 1 compared to group 2.

\begin{tabular}{|lllll|}
\hline Variable & Group 1 & Group 2 & p value & Significance \\
\hline Mean Induction to delivery interval (hours) & 10.27 & 4.11 & 0.001 (student t test) & Significant \\
\hline Mean MgSO4 dose (mg) & 61.67 & 54.75 & 0.017 & Significant \\
\hline
\end{tabular}

Table 7: Induction to delivery interval versus outcome in perinatal mortality.

\begin{tabular}{|lllll|}
\hline Outcome type & Outcome & I-D Interval (hours) & p value & Significance \\
\hline Perinatal & Yes & 10.71 & & \\
\hline Mortality & No & 5.16 & 0.025 & Significant \\
\hline
\end{tabular}

\section{DISCUSSION}

Of 92 women included in the study, 48 women had Bishop's less than or equal to 5 and 44 women had Bishop's $>5$. The groups were comparable with respect to baseline characteristics. Group II with $\mathrm{BS}>6$ had more vaginal deliveries indicating greater success of induction with favourable cervix (75\% group II (BS>6), $47.9 \%$ group I $(\mathrm{BS}<6)$ OR-3.26). Maternal mortality was similar in both the groups, one each. Maternal morbidity was higher in group I; however this difference was not statistically significant $(38.3 \%$ and $25.6 \%$ in group I and group II respectively; p -0.260).

Perinatal mortality (39.6\% in group I and $20.5 \%$ in group II) was significantly higher in group I. Although the rate of IUD and still births were similar, deaths due to HMD and birth asphyxia was higher with group I. Perinatal morbidity was also significantly higher with group I (25.6\% and $7.8 \%$ in group I and group II respectively).

Each group was further divided based on mode of deliveries and outcomes reanalysed. Perinatal mortality in group I was higher in vaginal delivery than in caesarean delivery. (56.5\% in vaginal and $24 \%$ in caesarean; $p$ value 0.021 ). Perinatal morbidity was also higher with vaginal mode of delivery but this difference was not statistically significant.

Secondary analysis was done to establish the cause for the difference. It was found that there was a direct association between induction to delivery interval and higher perinatal mortality. ( $\mathrm{p}$ value 0.021; OR-1.046). Mean magnesium sulphate does was higher in group I but this was not significantly associated with higher perinatal mortality

Perinatal deaths were due to still births, HMD and birth asphyxia. Maternal morbidity was marginally higher with caesarean deliveries. The duration of hospital stay was obviously higher in caesarean deliveries.

Our study shows that earlier delivery might improve perinatal outcome. Some authors have recommended that all women with eclampsia should be delivered within 12 hours of admission. 6 Sibai is of the opinion that if the 
gestational age is $<30$ weeks, caesarean delivery should be done, but if the gestational age is $>30$ weeks vaginal delivery is preferable. ${ }^{5}$

There are no studies comparing the mode of delivery or induction to delivery interval with outcome. A randomized pilot study by Seal et al have concluded that a policy of early caesarean delivery in eclampsia carrying $>34$ weeks is not associated with better outcomes. ${ }^{10}$ It has also stated that although a caesarean delivery may have improved foetal outcome, maternal morbidity was higher in caesarean deliveries. Seal et al had compared elective caesarean delivery with vaginal delivery, which might explain the similar outcomes. In our study caesarean was done in advanced labour, although the induction to delivery interval was shorter with caesarean deliveries, which might explain the better perinatal outcomes. Perinatal mortality in different observational studies of eclampsia varies from $16.4 \%-30 \% .^{3,4,11}$ Study by Seal et al had lower perinatal mortality compared to other studies. This is almost due to exclusion of cases with gestational age $<34$ weeks or absent foetal heart sound. ${ }^{10}$

In our study 32 weeks was taken as the cut off and lack of continuous electronic monitoring explains the higher perinatal mortality. We had limited access to this facility. Although this might not be the standard care, this situation is representative of low resource settings. Our study shows that induction to delivery rather than mode of delivery per se affects the outcome. Unfavourable cervix should be considered under the light of the above findings in deciding the management. Larger trials are required to establish the preferred duration of labour.

Limitation of this study was larger prospective studies are required to establish a cut off for induction to delivery interval. Due to lack of adequate number of similar studies, an extensive comparative analysis was not feasible.

\section{CONCLUSION}

Although maternal outcome was significantly different between the two groups, perinatal outcome was worse with unfavourable cervix. This can be attributed to increased induction to delivery time and vaginal route of delivery. Prolonged induction should be avoided in eclampsia.

\section{Funding: No funding sources}

Conflict of interest: None declared

Ethical approval: The study was approved by the Institutional Ethics Committee

\section{REFERENCES}

1. Maternal mortality in 2005: estimates developed by WHO, UNICEF, UNFPA, and the World Bank. 2007. Available at: https://apps.who.int/iris/bitstream/handle/10665/4380 7/9789244596210_rus.pdf. Accessed on June 8th, 2019.

2. Duley L. Pre-eclampsia, eclampsia, andhypertension. Clinical Evidence. 2008;2008:1402.

3. Which anticonvulsant for women with eclampsia? Evidence from the collaborative eclampsia trial Erratum in: Lancet. 1995;345:1455-63.

4. Pritchard JA. Pritchard SA. Standardised treatment of 159 consecutive cases of eclampsia. Am J Obstet Gynecol. 1975;123:543-52.

5. Sibai BM. Diagnosis, prevention and management of eclampsia. Obstet Gynecol. 2005;105:402-10.

6. World Health Organization. Managing complications in pregnancy and chilbirth: a Guide for Midwives and Doctors. Reprod Health. 2010.

7. Zwart JJ, Richters A, Ory F, de Vries JI, Bloemenkamp KW, van Roosmalen J. Eclampsia in The Netherlands. Obstet Gynecol. 2008;112:820-7.

8. Miguil M, Chekairi A. Eclampsia, study of 342 cases. Hypertens Pregnancy. 2008;27:103-11.

9. Hypertensive disorders in pregnancy. In: Cunningham FG, Leveno KJ, Bloom SL, Hauth JC, Gilstrap LC III, Wenstrom KD,eds. Williams obstetrics. 24 ${ }^{\text {th }}$ ed. New York; McGraw- Hill; 2014:728-771.

10. Seal SL, Ghosh D, Kamilya G. Does route of delivery affect maternal and perinatal outcome in women with eclampsia? A randomized controlled pilot study. Am J Obstet Gynecol. 2012;206:484.e17 .

11. Igberase GO, Ebeigbe PN. Eclampsia: ten years experience in a rural tertiary hospital in the Niger delta, Nigeria. J Obstet Gynaecol. 2006;26:414-7.

Cite this article as: Zulfeen M, Tatapudi R,

Sowjanya R. Does cervical favourability and mode of delivery affect the maternal and perinatal outcome in eclampsia?: a cohort study. Int J Reprod Contracept Obstet Gynecol 2019;8:3168-73. 